\section{A Study of Doppler velocimetry in pre-eclampsia patients, and their perinatal outcome}

\author{
Rahul Khatri1*, Bhoomika Jain ${ }^{1}$, Sabrina Mhapankar² and \\ Sushil Kumar ${ }^{3}$
}

\author{
1'Department of Obstetrics and Gynaecology, MGM Medical College and Research Centre, Navi \\ Mumbai, India \\ ${ }^{2}$ Assistant Professor, Department of Obstetrics and Gynaecology, MGM Medical College and \\ Research Centre, Navi Mumbai, India \\ ${ }^{3}$ Professor and HOD, Department of Obstetrics and Gynaecology, MGM Medical College and \\ Research Centre, Navi Mumbai, India
}

\section{Abstract}

Pre eclampsia and IUGR are important causes of maternal and perinatal morbidity and mortality. Pre eclampsia is a multisystem disorder, in normal pregnancies trophoblastic invasion transforms high resistance spiral arteries into low impedance uteroplacental circulation. This uteroplacental circulation remains incomplete in pre eclampsia and IUGR. This study is to correlate the Doppler Findings with the Fetal Outcome in pre eclampsia patiens, and helps decide appropriate time for delivery with least perinatal morbidity.

\section{More Information}

*Address for Correspondence: Dr. Rahul Khatri, MGM Medical College and Research Centre, Navi Mumbai, India, Tel: 9725572526 ; Email: rahul.y.khatri@gmail.com

Submitted: March 17, 2021

Approved: April 19, 2021

Published: April 21, 2021

How to cite this article: Khatri R, Jain B, Mhapankar S, Kumar S. Comparative study of continuous method and interrupted method of episiotomy in terms of healing of the surgical wound. Clin J Obstet Gynecol. 2021; 4: 044-049.

DOI: 10.29328/journal.cjog.1001085

Copyright: ๑ 2021 Khatri R, et al. This is an open access article distributed under the Creative Commons Attribution License, which permits unrestricted use, distribution, and reproduction in any medium, provided the original work is properly cited.

Keywords: Pre eclampsia; IUGR; Doppler changes; Neonatal complications

Check for updates

Open Access

\section{Introduction}

Pre eclampsia and IUGR are important causes of maternal and perinatal morbidity and mortality. In normal pregnancies trophoblastic invasion transforms high resistance spiral arteries into low impedance uteroplacental circulation. This uteroplacental circulation remains incomplete in pre eclampsia and IUGR [1].

\section{Pre eclampsia}

Pre eclampsia is a multisystem disorder of unknown aetiology characterized by development of hypertension to the extent of $140 / 90 \mathrm{~mm} \mathrm{hg}$ or more with proteinuria after $20^{\text {th }}$ week in previously normotensive and non proteinuric patient.

Abnormal development of uteroplacental circulation in the presence of pre-eclampsia [1,2].

A lack of endovascular infiltration by trophoblast into the myometrial portion of the placental bed spiral arteries is a consistent finding in the presence of preeclampsia. Classically it is held that second wave of endovascular trophoblastic invasion that proceeds in myometrial segments of the spiral arteries from 15 weeks, does not occur in patients who will develop preeclampsia. Lack of physiological conversion is not only apparent in the myometrial segments of spiral arteries, but also in the decidual parts of some of the vessels, so that a proportion of spiral arteries completely fail to undergo throphoblastic invasion and physiological changes. Since unconverted vessels retain 'high resistance/low capacitance' properties, the effect on the maternal blood supply to the placenta may be dramatically low. These may manifest as impaired growth of the baby or high bp with proteinuria i.e preeclampsia with its complications.

The persistence of high resistance to flow after 2426wks of gestation provide the rationale to investigate the placental circulation by Doppler and to predict development of Preeclampsia and fetal growth restriction.

\section{Doppler velocimetry}

The use of Doppler ultrasound for the evaluation of the fetal circulation is based on the physical principle of change in the frequency of sound wave when it is reflected by a moving object. This principle was described in 1842 by the Austrian physicist and mathematician Johann Christian Doppler. Doppler observed that the frequency of the sound waves reflected by a static object was identical to that before being reflected. In contrast, the frequency of the sound 
waves reflected form a moving object, such as blood inside a blood vessel, was different from the original frequency and proportional to the velocity of the moving object (Doppler Effect). Therefore, blood velocity and resistance to flow can be evaluated using Doppler Effect.

During Doppler fetal and maternal vessels are interrogated with ultrasound waves. Doppler study is a non-invasive method for evaluation of pathological hemodynamic changes not only in uteroplacental circulation but also in subsequently altered fetoplacental and fetal circulation.

Fetoplacental and fetal circulation.

- Doppler velocimetry indices include

$>$ Pulsatility Index (PI)

$>$ resistance Index $(\mathrm{RI})$

> Sytolic/dystolic velocity ratio (S/D ratio)

In this study we are going to use

Uterine artery Doppler to study uteroplacental circulation

Umbilical artery Doppler to study fetoplacental circulation

Middle cerebral artery Doppler to study fetal circulation

\section{Doppler changes}

Doppler changes in uteroplacental circulation represented by uterine artery

- Reduced uterine artery PI

- Diastolic notch

Doppler changes in fetoplacental circulation represented by umbilical artery

- Reverse diastolic flow

- Absent diastolic flow

Doppler changes in fetal circulation is represented by middle cerebral artery

- Higher diastolic flow in MCA = increased MCA

$$
\mathrm{PI}=\text { brain sparing effect }
$$

\section{Aims and objectives}

To Correlate the Doppler Findings with the Fetal Outcome.

\section{Methodology}

It is a prospective study of $(\mathrm{N}>=100)$ satisfying the inclusion and exclusion criteria.

1. Informed Consent will be taken from the relatives or the guardians and patient satisfying the inclusion criteria.

2. Doppler study will be done on the patients satisfying the inclusion criteria.

3. Demographic details will be recorded along with the history and clinical examination in the form of a case record form.

4. Data will be statistically analyzed at the end of data collection.

\section{Inclusion criteria}

Patients with preeclampsia characterized by

1. All the preeclamptic patients with or without complication.

2. Proteinuria. $>/=1+$ dipstick.

3. After 30 weeks of gestational age.

4. Consenting patients.

\section{Exclusion criteria}

1. patients with unreliable Last menstrual period details and not confirmed by first trimester scans.

2. non consenting patients.

\section{Results}

Cases in the study group: 100.

Table No. 1: Age Distribution.

Almost $90 \%$ of the patients in the study group fall in the age group of 18-30 years as a majority of deliveries occur in this age group in our set-up.

Table No. 2: Gravidity.

Majority of the patients in the study group were primigravidae. Pre-eclampsia is known to be more common in primigravidae [9].

\begin{tabular}{|c|c|c|}
\hline Table 1: Age Distribution. & & \\
\hline Age (in Years) & No. of Cases & Percent \\
\hline $18-25$ & 58 & $58 \%$ \\
\hline $26-30$ & 32 & $32 \%$ \\
\hline $31-35$ & 9 & $9 \%$ \\
\hline$>35$ & 1 & $1 \%$ \\
\hline Total & 100 & $100 \%$ \\
\hline
\end{tabular}

\begin{tabular}{|c|c|c|}
\hline Table 2: Gravidity. & & \\
\hline Gravidity & No. of Cases & Percent \\
\hline Primi & 56 & $56 \%$ \\
\hline Multigravida & 44 & $44 \%$ \\
\hline Total & 100 & $100 \%$ \\
\hline
\end{tabular}




\section{Table No. 3: Period of Gestation.}

Out of the total 100 patients 78 were in $37-40$ weeks period of gestation. 21 were between 28-36 weeks period of gestation.

Table No. 4: Associated conditions in the mother.

2 patients in the study group gave a history of eclampsia in the past pregnancy. 6 patients underwent emergency caesarean section in the past pregnancy.

Table No. 5: Preeclampsia.

Majority of the patients admitted (67\%) had a diastolic BP of $>100 \mathrm{~mm} \mathrm{Hg}$ on admission.

Table No. 6: Vessels involved as per abnormal Doppler Studies .

66 patients had normal Doppler velocimetry studies in the current series. 34 patients showed abnormal flow velocity waveform of which umbilical artery Doppler formed a majority of cases. 2 patients showed involvement of all 3 vessels on Doppler.

Table No. 7: Umbilical Doppler Velocimetry and Perinatal Outcome.

Of the total patients, 10 of them had absent end diastolic flow of these 10 patients, 8 underwent caesarean section and 2 underwent vaginal trial. There 5 neonatal deaths. The overall prognosis was found to be worst in the subgroup with absent end diastolic flow.

Table No. 8: Uterine Artery Doppler.

10 patients showed diastolic notching. 2 underwent vaginal trial and 8 patients were taken up for caesarean section. There were 2 neonatal deaths. One patient showed reduced PI and was given a vaginal trial.

Table No. 9: Velocimetry study involving alternation of two vessels and subsequent outcome.

Multiple vessel involvement was associated with adverse fetal outcome as is noted in the table. 2 patients had abnormal uterine + umbilical artery velocimetry, there were neonatal deaths after a stormy perinatal outcome in both cases who underwent emergency caesarean section in this group. There were 6 patients who had abnormal umbilical + middle cerebral artery velocimetry. All 6 cases underwent caesarean section in the subgroup with. Out of 6, 5 had late neonatal deaths. Multiple vessel involvement was associated with very poor prognosis.

Table No.10: Duration between Last Doppler Ultrasound and Delivery.

The average decision to delivery interval in the current study was $24 \mathrm{hrs}$. The decisions were largely influenced by stabilization of maternal hypertension, avoiding respiratory distress syndrome in some neonates by administering 2 doses of corticosteroids 12 hours apart. Patients were closely involved in the decision making process. In patients with absent or reversed umbilical end diastolic flow velocity, the average decision to delivery interval was 8 hours in a majority of patients.

\section{Table No.11: Indication Associated with LSCS.}

53 patients out of 100 underwent caesarean section in the study group. 18 underwent caesarean section for abnormal fetal heart rate patterns out of which 7 were associated with meconium stained liquor. 10 underwent caesarean section for abnormal Doppler parameters.

Table No. 12: Average Baby Weight (in kg).

The patients with abnormal Doppler parameters were delivered preterm and had to get admitted in the nicu for $>48$ hrs due to low birth weight. But those patients who inspite of being pre eclamptic but having a normal Doppler study had an avg baby wt between $2-3 \mathrm{~kg}$.

Table No. 13: Neonatal Complications.

11 babies with abnormal umbilical artery Doppler had nicu stay more than $48 \mathrm{hrs}$ and also other neonatal complications. The second in the row was involvement of umbilical and MCA Doppler waveforms with maximum neonatal complications.

\begin{tabular}{|c|c|c|}
\hline Table 3: Period of Gestation. & \multicolumn{2}{|c|}{} \\
\hline Period of Gestation (Weeks) & No. of Cases & Percent \\
\hline $28-36$ & 21 & $21 \%$ \\
\hline $37-40$ & 78 & $78 \%$ \\
\hline$>40$ & 1 & $1 \%$ \\
\hline Total & 100 & $100 \%$ \\
\hline
\end{tabular}

\begin{tabular}{|c|c|c|}
\hline Table 4: Associated conditions in the mother. & \multicolumn{2}{l|}{} \\
\hline Associated conditions in the mother & No. of Cases & Percent \\
\hline PREV LSCS & 1 & $6.7 \%$ \\
\hline PREV LSCS WITH GDM & 1 & $6.7 \%$ \\
\hline H/O ECLAMPSIA & 2 & $13.3 \%$ \\
\hline PREV 2 LSCS & 1 & $6.7 \%$ \\
\hline PREV LSCS & 6 & $40.0 \%$ \\
\hline RPL & 2 & $13.3 \%$ \\
\hline TORCH + & 1 & $6.7 \%$ \\
\hline TWIN GESTATN & 1 & $6.7 \%$ \\
\hline Total & 15 & $100.0 \%$ \\
\hline
\end{tabular}

\begin{tabular}{|c|c|c|}
\hline Preeclampsia & No. of Cases & Percent \\
\hline Mild & 33 & $33 \%$ \\
\hline Severe & 67 & $67 \%$ \\
\hline Total & 100 & $100 \%$ \\
\hline
\end{tabular}

\begin{tabular}{|c|c|c|}
\hline Table 6: Vessels involved as per abnormal Doppler Studies. \\
\hline Vessels involved & No. of Cases & Percent \\
\hline Umbilical artery & 15 & $15 \%$ \\
\hline Umbilical + Uterine Artery & 2 & $2 \%$ \\
\hline Umbilical Artery + Middle Cerebral Artery & 6 & $6 \%$ \\
\hline Uterine Artery & 11 & $11 \%$ \\
\hline Middle Cerebral Artery & 8 & $8 \%$ \\
\hline All three vessels & 2 & $2 \%$ \\
\hline
\end{tabular}


Table 7: Umbilical Doppler Velocimetry and Perinatal Outcome.

\begin{tabular}{|c|c|c|c|c|c|c|c|}
\hline \multirow{3}{*}{$\begin{array}{c}\text { Parameters } \\
\text { Altered }\end{array}$} & \multirow{3}{*}{$\begin{array}{l}\text { No. of } \\
\text { Cases }\end{array}$} & \multicolumn{6}{|c|}{ Mode of Delivery } \\
\hline & & \multicolumn{3}{|c|}{ Vaginal } & \multicolumn{3}{|c|}{ LSCS } \\
\hline & & Live Birth & Still Birth & NND & Live Birth & Still Birth & NND \\
\hline $\begin{array}{l}\text { Increased } \\
\text { resistance }\end{array}$ & - & - & - & - & - & - & - \\
\hline Absent EDF & 10 & 2 & - & - & 8 & - & 5 \\
\hline Reversed EDF & 1 & - & - & - & 1 & - & - \\
\hline
\end{tabular}

Table 8: Uterine Artery Doppler.

\begin{tabular}{|c|c|c|c|c|c|c|c|}
\hline \multirow{2}{*}{$\begin{array}{c}\text { Parameters } \\
\text { altered }\end{array}$} & $\begin{array}{c}\text { No. of } \\
\text { Cases }\end{array}$ & \multicolumn{5}{|c|}{ Vaginal } \\
\cline { 3 - 9 } & Live Birth & Still Birth & NND & Live Birth & Still Birth & NND \\
\hline $\begin{array}{c}\text { Diastolic } \\
\text { notching }\end{array}$ & 10 & 2 & - & - & 8 & - & 2 \\
\hline Reduced PI & 1 & 1 & - & - & - & - & - \\
\hline
\end{tabular}

Table 9: Velocimetry study involving alternation of two vessels and subsequent outcome.

\begin{tabular}{|c|c|c|c|c|c|c|c|}
\hline & & \multicolumn{5}{|c|}{ Mode of Deliver } \\
\hline & $\begin{array}{c}\text { No. of } \\
\text { Cases }\end{array}$ & \multicolumn{3}{|c|}{ Vaginal } & \multicolumn{3}{c|}{ LSCS } \\
\hline & & $\begin{array}{c}\text { Live } \\
\text { Birth }\end{array}$ & $\begin{array}{c}\text { Still } \\
\text { Birth }\end{array}$ & NND & $\begin{array}{c}\text { Live } \\
\text { Birth }\end{array}$ & $\begin{array}{c}\text { Still } \\
\text { Birth }\end{array}$ & NND \\
\hline Uterine artery+ umbilical artery & 2 & - & - & - & 2 & - & 2 \\
\hline $\begin{array}{c}\text { Umbilical artery + middle } \\
\text { cerebral artery }\end{array}$ & 6 & - & - & - & 6 & - & 5 \\
\hline Middle cerebral & 8 & - & - & - & 8 & - & 5 \\
\hline Three vessel involvement & 2 & - & - & - & 2 & - & 2 \\
\hline
\end{tabular}

Table 10: Duration between Last Doppler Ultrasound and Delivery.

\begin{tabular}{|c|c|c|}
\hline Duration & No. of Cases & Percent \\
\hline$<4 \mathrm{hrs}$ & 1 & $1 \%$ \\
\hline $4-8 \mathrm{hrs}$ & 79 & $79 \%$ \\
\hline $9-12 \mathrm{hrs}$ & 17 & $17 \%$ \\
\hline$>12 \mathrm{hrs}$ & 3 & $3 \%$ \\
\hline Total & 100 & $100 \%$ \\
\hline
\end{tabular}

Table 11: Indication Associated with LSCS.

\begin{tabular}{|c|c|c|}
\hline Indication & No. of Cases & Percent \\
\hline PREV LSCS & 10 & $18.9 \%$ \\
\hline FD & 11 & $20.8 \%$ \\
\hline UNCONTROLLED HTN & 1 & $1.9 \%$ \\
\hline MSAF+FD & 7 & $13.2 \%$ \\
\hline FOI & 2 & $3.8 \%$ \\
\hline DOPPLER CHANGES(DC) & 10 & $18.9 \%$ \\
\hline NPOL & 3 & $5.7 \%$ \\
\hline TWIN GESTATION & 1 & $1.9 \%$ \\
\hline OLIGO & 2 & $3.8 \%$ \\
\hline CPD & 4 & $7.5 \%$ \\
\hline PREV 2 LSCS & 2 & $3.8 \%$ \\
\hline Total & 53 & $100.0 \%$ \\
\hline
\end{tabular}

Table 12: Average Baby Weight (in kg).

\begin{tabular}{|c|c|c|}
\hline Baby Weight & No. of Cases & Percentage \\
\hline$<1$ & 2 & $2 \%$ \\
\hline $1-1.5$ & 3 & $3 \%$ \\
\hline $1.6-2$ & 18 & $18 \%$ \\
\hline $2.1-2.5$ & 22 & $22 \%$ \\
\hline $2.6-3$ & 33 & $33 \%$ \\
\hline $3.1-3.5$ & 15 & $15 \%$ \\
\hline$>3.5$ & 7 & $7 \%$ \\
\hline Total & 100 & $100 \%$ \\
\hline
\end{tabular}

Table 13: Neonatal Complications.

\begin{tabular}{|c|c|c|c|c|}
$\begin{array}{c}\text { Neonatal } \\
\text { complications }\end{array}$ & $\begin{array}{c}\text { Umbilical } \\
\text { Artery }\end{array}$ & $\begin{array}{c}\text { Uterine } \\
\text { Artery }\end{array}$ & $\begin{array}{c}\text { Umbilical + Uterine } \\
\text { artery }\end{array}$ & $\begin{array}{c}\text { Umbilical + } \\
\text { MCA }\end{array}$ \\
\hline $\begin{array}{c}\text { Birth Asphyxia } \\
\text { Sepsis }\end{array}$ & - & - & - & - \\
Jaundice & 1 & - & - & 1 \\
Congenital & 9 & 2 & 2 & 5 \\
anomaly & - & - & - & - \\
IUGR & 7 & 3 & 2 & 4 \\
Ventilatory Support & 6 & 2 & 2 & 4 \\
Any other & 1 & 1 & - & 1 \\
Neonatal death & 5 & 2 & 2 & 5 \\
NICU> 48 hrs & 11 & 4 & 2 & 6
\end{tabular}

\section{Discussion}

Preeclampsia and eclampsia have been recognized as a potentially fatal complication of pregnancy challenging obstetricians for more than a century. It complicates $3 \%$ $10 \%$ of pregnancies and is responsible for a large proportion of maternal and perinatal morbidity and mortality [1]. It is well known that despite extensive research into the etiopathogenesis of this condition expediting delivery of the fetus and placenta have still remained the only effective treatment. The exact timing of delivery remains an issue of debate to most obstetricians.

The present prospective observational study includes 100 cases of preeclampsia admitted in a tertiary referral centre. Majority of the delivered patients in the institute have limited resources. Antenatal patients detected to have hypertension were hospitalized and a serial monitoring of the blood pressure was maintained. The baseline hematological investigations performed include a complete hemogram, coagulation profile, liver and renal function tests and urine analysis. A fundoscopic examination is performed by the ophthalmologist to visualize the grades of hypertensive changes. Short acting or longacting anti hypertensives are administered in the minimum dosage required and stepped up depending on the BP reading. A baseline obstetric scan is performed for every patient to note the composite gestational age. Maternal surveillance includes BP charting and monitoring of symptoms like headache, epigastric distress, blurring of vision, swelling of the body and altered urine output. Fetal surveillance included a daily fetal movement count and a daily cardiotocograph. A Doppler ultrasound is performed whenever there is a high degree of clinical suspicion of fetal growth lag. The decision to perform a Doppler velocimetry is very individualized and based on the clinical judgment of a senior consultant obstetrician.

\section{Demographic perspectives}

In the present study, analysis of demographic data showed that a majority of the patients with preeclampsia were in the age group of $18-25$ years. $33 \%$ of the patients were in the age group of 25-30 years. Majority of the patients (56\%) were primigravidae. Amongst the study group of 100 patients, 67 had severe preeclampsia. As mentioned previously, all these 
patients had been admitted as identified high risk cases and appropriate treatment was initiated depending on the severity of preeclampsia.

\section{Umbilical artery Doppler}

In the presentstudy, abnormal umbilical artery flowvelocity waveforms were exclusively seen in 11 patients. Amongst the 11 patients with abnormal umbilical artery Doppler, 10 patients had absent diastolic flow in the umbilical artery and 1 patients had reversed diastolic flow in the umbilical artery. 9 out of 10 patients in this group were delivered by LSCS. There were 5 neonatal deaths. All the 11 babies were admitted for more than 48 hours in the NICU. The main complications seen in the babies in this group were jaundice, convulsions, IUGR and 6 babies required ventilatory support. Though the present study group is small the observations reflect a good specificity of umbilical velocimetry in relation to perinatal morbidity.

A strong relationship between the umbilical artery Doppler indices and fetal well-being has been demonstrated in several other studies. Elevation of umbilical artery Doppler indices in the presence of positive end diastolic flow is associated with hypoxemia at a steady state Weiner, et al (1990), Bilardo, et al. (1990) [3]. Absent end diastolic flow in the umbilical artery is associated with a significant worsening of hypoxemia and acidemia may be present [4]. Yoon and Lee in 1994 in the American Journal of Obstetrics and Gynaecology [5], demonstrated that poor perinatal outcome occurred more frequently in women with an abnormal umbilical artery waveform than those with a normal waveform. Indeed, the rates of preterm delivery, caesarean section for fetal distress, admission to the intensive care, occurrence of significant neonatal morbidity and perinatal death were significantly higher in the patients with an abnormal waveform. Ducey, et al. [6] reported that $65 \%$ of patients of preeclampsia had an abnormal umbilical artery waveform. They suggested that the severity of the disease correlates with the degree of placental ischemia occurring in patients with preeclampsia and that patients with abnormal Doppler velocirnetry have poorer outcomes.

Therefore, a summative inference is that umbilical artery Doppler should be offered as a primary and single best line of assessment of the fetoplacental circulation in high-risk pregnant women with preeclampsia and suspected fetal growth restriction. There is good evidence from the Cochrane Pregnancy and Childbirth database based on the outcomes of randomized trials to suggest the use of umbilical artery Doppler for a beneficial effect on perinatal outcome [7]. At an early gestational age reduced or absent umbilical artery end diastolic flow is an indication for increased fetal surveillance, but not necessarily for immediate delivery. However closer to term, severe placental insufficiency reflected by absent umbilical artery end diastolic flow velocity is an indication for delivery. Fetuses with absent umbilical end diastolic flow are more severely growth restricted and are at a higher risk of perinatal morbidity and mortality. They require delivery at an earlier gestational age than those with reverse end diastolic flow.

\section{Uterine artery Doppler}

In the present study, diastolic notching was seen in 10 patients. 2 patients had an abnormal umbilical artery flow velocity waveform along with uterine artery notching and 2 patients had an elevated pulsatility index in the middle cerebral artery. 8 patients in this category delivered by caesarean section. The delivered neonates had significantly lower birth weight percentiles. 2 babies developed jaundice, 3 were IUGR and 4 babies spent $>48 \mathrm{hrs}$ in the intensive care unit. 2 babies required ventilatory support.

In hypertensive gravidas with a notch in the uterine artery flow velocity waveforms, the impedance to flow in the uterine vascular bed is significantly higher than it is in hypertensive patients without a notch. This suggests that the appearance of a notch reflects a higher impedance to blood flow and the momentary tendency of the uterine artery to close in late systole or early diastole. In the present study, an adverse pregnancy outcome was observed in all patients with diastolic notching regardless of the flow velocity waveforms in the umbilical artery. Additionally, when this pattern in the uterine artery was associated with an increased impedance to flow in the umbilical artery, the incidence of fetal growth restriction increased.

In a large study of 140 hypertensive pregnant patients, Israel Thaler, et al. [8] reported the additional correlation of the presence or absence of a systolic or diastolic notch along with the resistance indices in the uterine arteries on both sides of the uterus. They found that those patients with notches had a significantly higher rate of fetal growth restriction and caesarean delivery (64\% vs. 12.9\%) because of fetal distress (56\% vs. 29.7\%) Vergani, et al. [9] also found that the presence of abnormal doppler waveforms at the uterine arteries is associated with a 4 fold increase of adverse neonatal outcome. Park, et al. in the American Journal of Obstetrics and Gynecology have shown in their study of 2361 pre eclamptic patients after 28 weeks of gestation, the group with notches had significant differences in the incidence of IUGR (44.7\% vs. 8.9\%) and fetal distress (34.2\% vs. 3\%).

Therefore, the inference is that abnormal uterine artery spectra could be carefully taken into consideration during the decision-making process in individualized situations. Currently there is still a lack of robust evidence by controlled randomized trials to suggest the regular use of uterine artery Doppler measurements and their potential role in predicting pregnancy complications associated with abnormal uteroplacental perfusion.

\section{Middle cerebral artery}

In the present study, the pulsatility index of the middle 
cerebral artery was increased in 8 patients with severe IUGR. Of these 6 patients had a simultaneous increased resistance pattern in the umbilical artery flow velocity waveforms as well. There were 5 neonatal deaths in this group.

Middle cerebral artery changes are associated with SGA fetuses. Vyas and Nicolaides, et al. showed that the pulsatility index of the middle cerebral artery was significantly lower and the mean systolic velocity was higher in SGA fetuses than the respective reference ranges for normal fetuses throughout gestation. The redistribution in hypoxemic SGA fetuses may be transitory with worsening of 02 deficit; the pulsatility index tend to rise which may be attributable to the development of brain edema. He reported a $27 \%$ rate of redistribution among SGA fetuses. It is interesting to note that the changes in the middle cerebral artery were also accompanied by changes in the umbilical artery flow velocity waveforms in this study. Umbilical artery flow velocimetry is easy to perform, not only with color flow imaging, which was used in all our patients, but also with inexpensive continuous wave equipment making the test more suitable as a primary screening tool. The correct visualization of the middle cerebral artery is mandatory to avoid false positive results and cannot be obtained accurately with continuous wave equipment. Strigini, et al. [10] demonstrated that umbilical artery velocimetry indicates that the vascular structure of the placenta may be abnormal, with or without adverse perinatal outcome. Within this subgroup, at risk for chronic hypoxia of placental origin, abnormal cerebral artery velocimetry indicates that hypoxia has occurred thus endangering the fetus. In fact, he reported that when both umbilical and cerebral velocities were abnormal, $60 \%$ fetuses were SGA and had a stormy perinatal outcome.

Although an increase in the cerebral arterial end diastolic flow velocimetry may reflect chronic fetal hypoxemia there is no evidence that this measurement will provide additional benefit to perinatal outcome beyond the assessment of the umbilical circulation alone.

\section{Decision to delivery interval}

In the present study, the average interval observed between abnormal Doppler findings and delivery of the baby was found to be $<24 \mathrm{hrs}(70 \%) .78$ patients had a decision to delivery interval of 4-8 hrs and 17 patients showed a decision to delivery interval of 9-12 hrs. Analysis showed that the decision to delivery interval was largely influenced by 2 factors. The primary concern was the stabilization of maternal hypertension before planning delivery. The second concern was to avoid respiratory distress syndrome in the premature neonate and enhance lung maturity by administering 2 doses of corticosteroids (betamethasone) $12 \mathrm{hrs}$ apart. Weekly Doppler estimation was offered in all patients included in this study. Hence the decision to deliver the patient was largely dominated by a panoramic and holistic assessment of the clinical situation in every case along with the help of the Doppler study. Patients were closely involved in the crucial decision-making process making them aware of the possibility of adverse perinatal outcome. There was a close liaison with the neonatal intensive care unit to ensure the availability of beds for the neonate.

Larger studies would be desirable to determine whether the presence of IUGR or oligohydramnios both at admission results in a significantly higher rate of deterioration in fetal condition during expectant management of preeclampsia.

\section{Conclusion}

Current evidence suggests that the logical approach to manage suspected uteroplacental insufficiency is a weekly estimation of umbilical artery Doppler. Serial Doppler velocimetry and fetal heart rate analysis definitely resulted in more live births.

\section{References}

1. Cunningham FG, Lenevo KJ, Bloom SL, Hauth JC, Rouse DJ, et al. Williams Obstetrics. 23rd edition.

2. Arias F, Daftary SN, Bhide AG. Practical guide to High-Risk pregnancy and delivery: 3rd edition. Chp 1, 22-26.

3. Bilardo $\mathrm{CM}$, Nicolaides $\mathrm{KH}$, Campbell S. Doppler measurements of fetal and uteroplacental circulations: Relationship with umbilical venous blood gases measured at cordocentesis. Am J Obstet Gynecol. 1990; 162: $115-120$.

4. Nicolaides KH, Bilardo CM, Soothill PW, Campbell S. Absence of end diastolic frequencies in umbilical artery: A sign of fetal hypoxia and acidosis. BMJ 1988; 297: 1026-1027.

PubMed: https://pubmed.ncbi.nlm.nih.gov/3142596/

5. Yoon $\mathrm{BH}$, Lee $\mathrm{CM}$, Kim SW. An abnormal umbilical artery waveform: A strong and independent predictor of adverse perinatal outcome in patients with preeclampsia. Am J Obstet Gynecol. 1994; 171: 713-721.

6. Ducey J, Schulman H, Farmakides G, Rochelson B, Bracero L, et al. A classification of hypertension in pregnancy based on $\mathrm{h}$ Doppler velocimet. Am J Obstet Gynecol. 1987; 157: 680-685.

7. National High School Pressure Education Program: Working group Report On High School Pressure in Pregnancy. Am J Obstet Gynacol. 2000; 183: 51.

8. Thaler I, Weiner Z, Itskovitz J. Systolic or Diastolic notch in umbilical artery blood Flow Velocity Waveforms in hypertensive pregnant patients relationship to outcome. Obstet Gynecol. 1992; 80: 277-282. PubMed: https://pubmed.ncbi.nlm.nih.gov/1635744/

9. Vergani $\mathrm{P}$, Rondagia $\mathrm{N}$, Andreotti $\mathrm{C}$, Arreghini A, Teruzzi M, et al Prognostic value of uterine artery Doppler velocimetry in growth restricted fetuses delivered near term. Am J Obstet Gynecol. 2002; 1987: 932-936.

PubMed: https://pubmed.ncbi.nlm.nih.gov/12388980/

10. Strigini FA, De Luca G, Lencioni G, Scida P, Giusti G, et al. Middle Cerebral Artery Velocimetry: Different Clinical Relevance Depending on Umbilical Velocimetry. Obstet Gynecol. 1997; 9: 953-957.

PubMed: https://pubmed.ncbi.nlm.nih.gov/9397110/ 